\title{
Does another Euclidean plane exist other than the parasphere?
}

\author{
Endre Székely \\ Independent researcher \\ ORCID ID: 0000-0001-9724-3700 \\ HUNGARY, Budapest, 1132 Csandy street 8. \\ email: ndree123@gmail.com
}

\begin{abstract}
It is shown that for the question of the title the answer is yes. We construct a plane in the hyperbolic space which is Euclidean.
\end{abstract}

Let us use the symbols on the Figure 9. of Bolyai's Appendix [1] and take a fourth plane (more precisely a half plane) which intersects the ABNM plane at an angle of $\frac{\pi}{2}$ and intersects the APM and the BND half planes.

According to the proof of Bolyai, the half planes APM resp. BND are intersecting each other if the angle between the APM and ABNM planes is $\frac{\pi}{2}$ and the angle between BND and ABNM (half) planes is arbitrarily less than $\frac{\pi}{2}$. Then it follows that the intersection lines of the fourth plane with the APM and BND half planes, respectively, are also intersecting each other. This means that in the fourth plane the Euclidean geometry is valid.

To describe the above construction in more detail, let us take a point $R$ on the $A M$ line and a point $Z$ on the $B N$ line such that the $R Z$ line is perpendicular to $\mathrm{BN}$.

2010 Mathematics Subject Classification: 51M09, 51M15

Key words and phrases: hyperbolic plane, Euclidean geometry 


\section{\$9}

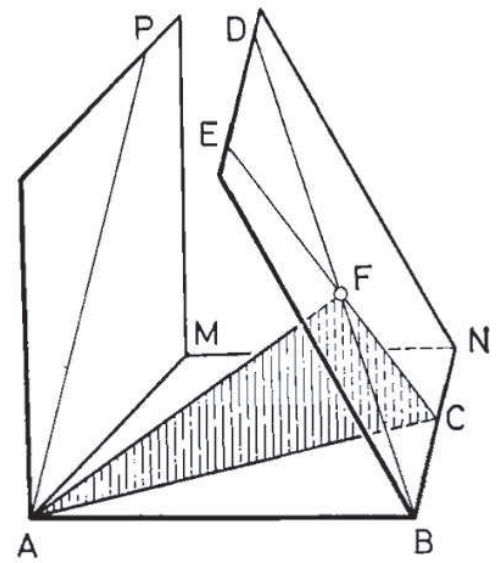

Figure 9

Take a plane containing the RZ line, which intersects the $A B N M$ plane at $\frac{\pi}{2}$ angle ( $\delta$ plane). Take a half plane containing $A M$ intersecting the $A B N M$ plane at $\frac{\pi}{2}$ angle (this will be denoted as AMP plane or $\beta$ plane), and a half plane containing $B N$, which intersects the $A B N M$ plane at an angle less than $\frac{\pi}{2}$ (BND plane or $\alpha$ plane). Then, according to Bolyais proof, the two half planes ( $\alpha$ and $\beta$ half plane) intersect each other and the plane through RZ ( $\delta$ plane) intersects the other two, and the intersection lines of $\delta$ plane with the $\beta$ plane and $\alpha$ plane, respectively, also intersect each other while the $\alpha$ half planes dihedral angle with the AMBN plane less then $\frac{\pi}{2}$. (As Bolyai has proven, if the $\alpha$ half plane intersects the $A B N M$ plane at an angle arbitrarily smaller than $\frac{\pi}{2}$, then the half planes $\alpha$ and $\beta$ intersect each other.) Then it follows: in the $\delta$ plane the Euclidean geometry seems to be valid. The intersection line of the $\alpha$ and $\beta$ half planes does not intersect the ABNM plane, because the AM and $\mathrm{BN}$ lines are parallel.

Let us denote the intersection line of $\alpha$ and $\beta$ half planes by $K$. The intersection lines of $\delta$ plane with the $\alpha$ and $\beta$ half planes, respectively, both intersect $\mathrm{K}$, because as Bolyai implicitly uses the statement: if there are two parallel lines in a plane and from one of the two we draw a perpendicular line in the plane, this latter line will intersect the other line. Also, $\mathrm{K}$ is parallel with AM and $B N$. If $K$ would intersect $A M$ or $B N$, then these two latter lines would also intersect each other. 
Similar results were published recently by Miroslava Antic [2].

A very interesting related paper is published by Zoltán Győrfy [3].

\section{Acknowledgements}

It is a pleasure to express my thanks to my friend Éva Gramiss and to my son Ádám Székely for their constant help while writing this article, to my friend Dr. Zoltán Győrfy for discussing the content of this paper and to my friend Dr. Tamás Szabados for reading the final version of this paper and for his valuable advice. Special gratitude is due to Professor Tibor Weszely, the well-known expert of non-Euclidean geometry for reading an earlier version of this paper.

\section{References}

[1] Bolyai János, Appendix, North-Holland Mathematics Studies 138 (1987) Ferenc Kárteszi (ed), 80., http://dide.ker.sch.gr/emekerkyra/books/ Bolyai, J\%20Theory $\% 20$ of $\% 20$ Space.pdf

[2] Miroslava Antic, The equidistant involution of the hyperbolic plane and two models of the Euclidean plane geometry, Journal of Geometry Vol. 04, Issue 2, (2013), 201-212

[3] Győrfy Zoltán, Az egyenes vonal természetéröl - Saccheri és az elpaccolt Mennyország (On the nature of the straight line - Saccheri and the missed Heaven), Ponticulus Hungaricus, XVI. évf. 5. (2012), http://members . iif.hu/visontay/ponticulus/rovatok/limes/gyorfi-saccheri.html 